\title{
Onderwijs rond chronisch zieken in de medische curricula van Nederland
}

\author{
J. Pols, J. van der Griend
}

\section{Samenvatting}

Inleiding: Een arts wordt geacht niet alleen op medisch-biologisch terrein adequaat te handelen, maar ook aandacht te hebben voor psychosociale en maatschappelijke gevolgen van de aandoening voor de patiënt. Op de laatste twee gebieden ervaren chronisch zieken onvoldoende aandacht van (medische) hulpverleners. In de literatuur wordt al sinds 1966 gewezen op tekorten in de voorbereiding van artsen op dit terrein.

Doel: Als uitgangspunt voor onderwijsverbeteringen wilden wij meer zicht krijgen op de aandacht in het medisch onderwijs voor de gevolgen van chronische ziekten op psychosociaal en maatschappelijk terrein en de rol van de arts hierbij en ook de verdeling van deze aandacht over kennis, vaardigheden en attitudes.

Methode: Uit studiegidsen is informatie verzameld over het onderwijs met betrekking tot chronische ziekten. De informatie is ter controle voorgelegd aan de onderwijsinstituten en geordend waarbij onderscheid is gemaakt tussen ziekteoverstijgend en ziektegebonden onderwijs. Ook is van het predoctorale onderwijs gekeken of het gericht is op kennis, vaardigheden of attituden. Vervolgens is een indeling gemaakt naar inhoudelijke categorieën. Resultaten: Het algemene beeld dat naar voren komt, is dat van curricula waarvan het onderwijs sterk biomedisch en kennisgeoriënteerd is. Psychosociale en maatschappelijke aspecten komen beperkt aan bod en er vindt geen systematische vertaling plaats naar het vaardigheidsonderwijs en de co-assistentschappen.

Conclusie: Het ontbreekt aan systematische aandacht in het onderwijs voor de psychosociale en maatschappelijke gevolgen van chronische ziekten en de rol van de arts op dit gebied. Het wordt tijd dat gevolg wordt gegeven aan oproepen om de veelvuldig gesignaleerde onderwijslacunes aan te pakken. (Pols J, Griend J van der. Onderwijs rond chronisch zieken in de medische curricula van Nederland. Tijdschrift voor Medisch Onderwijs 2001;20(2):46-53.)

\section{Inleiding}

Nederland kent veel mensen met een chronische aandoening. Al naar gelang de gehanteerde definitie varieert de schatting van $10 \%$ tot $30 \%$ van de bevolking (1,5 tot 4,5 miljoen individuen). ${ }^{1}$ Dit percentage zal verder stijgen onder invloed van de toenemende levensverwachting, de toenemende vergrijzing en verbeteringen in diagnostiek en behandelmethoden. Voor de meest frequent voorkomende chronische aandoeningen wordt tot 2015 een stijgingspercentage verwacht van gemiddeld $31 \%$ per ziekte. ${ }^{1}$
Vooral bij chronisch zieken moeten artsen niet alleen op medisch-biologisch terrein adequaat handelen, maar ook aandacht hebben voor psychosociale en maatschappelijke gevolgen van de aandoening voor de patiënt. Het gebrekkig signaleren van problemen op die laatste gebieden wordt door patiënten op dit moment gezien als een belangrijk knelpunt in de zorgverlening door (medische) hulpverleners. ${ }^{2}$ De overheid probeert hierin verandering te brengen door een beleid waarmee gestimuleerd wordt dat psychosociale zorg integraal onderdeel uitmaakt van de 
reguliere zorg voor mensen met een chronische aandoening. ${ }^{3}$ Dit resulteert in een grotere aandacht voor dit aspect in bij- en nascholingscursussen. Een voorbeeld daarvan is het nascholingsmateriaal van het Nederlands Huisartsen Genootschap, dat vooral gericht is op de gevolgen van de ziekte voor patiënten en de naasten, en niet zozeer op diagnostiek en behandeling. ${ }^{4}$

De vraag rijst in welke mate studenten geneeskunde tijdens hun studie worden voorbereid op contacten met chronisch zieken. Literatuuronderzoek is wat dat betreft niet geruststellend. Vanaf 1966 is er een doorlopende reeks publicaties verschenen waarin steeds opnieuw wordt geconstateerd dat er lacunes bestaan. De aanbevelingen tot aanpassingen in het bestaande onderwijs schetsen daarvan een beeld. Zo vindt men dat artsen zowel medisch als emotioneel beter moeten worden voorbereid op het contact met chronisch zieken. ${ }^{5}$ Artsen moeten leren de actuele situatie van een patiënt te beoordelen in het licht van de toekomstige ontwikkelingen van de aandoening om daar in de behandeling rekening mee te kunnen houden. ${ }^{6}$ Er moet meer aandacht komen voor het samenwerken met verpleegkundigen en paramedici. ${ }^{7} 8$ Studenten moeten beter getraind worden in patient-education. ${ }^{9} \mathrm{Er}$ is betere training nodig in het brengen van slecht nieuws en de zorg voor stervenden. ${ }^{6}$ Ten slotte moet er meer aandacht komen voor de geriatrie. ${ }^{7} 1011$ Deze reeks artikelen vindt haar voorlopig eind in 1998, als Cohen nog eens op een rij zet wat elke arts rond chronisch zieken moet weten en kunnen en welke beroepshouding noodzakelijk is voor de begeleiding van chronisch zieken. ${ }^{12}$

De veranderingen in de gezondheidszorg en de geconstateerde lacunes leiden er in Nederland toe dat men zich in het medisch onderwijs bezint op de manier waarop studenten voorbereid worden op contacten met chronisch zieken. De Faculteit der Medische Wetenschappen in Groningen heeft een project gerealiseerd onder de titel Onderwijs rond chronisch zieken in Curriculum 2000.13 Binnen dit project bestond de behoefte om meer zicht te krijgen op het bestaande onderwijs in Nederland rond chronisch zieken en de gevolgen van chronische aandoeningen op psychosociaal en maatschappelijk terrein. Er is antwoord gezocht op de volgende vragen:

1. In hoeverre wordt er door de Nederlandse faculteiten geneeskunde aandacht besteed aan de gevolgen van chronische aandoeningen op psychosociaal en maatschappelijk terrein en de rol van de arts op die gebieden.

2. Hoe is deze aandacht verdeeld over het verwerven van kennis en vaardigheden en de bewustwording van attitudes?

\section{Methode}

Informatie over het onderwijs is via studiegidsen verzameld en ter controle aan de directies van de onderwijsinstituten voorgelegd. Daarna heeft een analyse plaatsgevonden van de onderwerpen die in het onderwijs aan bod komen. De procedures worden hieronder nader toegelicht.

Op basis van informatie uit de studiegidsen van het studiejaar 1998-1999 zijn overzichten gemaakt van het onderwijs rond chronisch zieken aan de acht Nederlandse faculteiten. Daarbij is gekeken naar het predoctorale kernonderwijs, de co-assistentschappen en het keuzeonderwijs. In de overzichten is de informatie uit de studiegidsen opgenomen en geordend.

In de eerste plaats is in het predoctorale kernonderwijs een ordening aangebracht naar ziekteoverstijgende en ziektegebonden onderwerpen. Onder 'ziekteoverstijgend' is onderwijs verstaan waarin problematiek aan de orde wordt gesteld die in meer of mindere mate een rol speelt bij alle chronisch zieken. Dit geldt bijvoorbeeld 
voor de algemene gevolgen van chronisch ziek zijn, de daaruit voortvloeiende zorgbehoefte en de organisatie van de zorgverlening. Onder 'ziektegebonden' wordt onderwijs verstaan waarin een specifieke ziekte of aandoening centraal staat en waarbij ook wordt ingegaan op de psychosociale en maatschappelijke gevolgen, bijvoorbeeld de behandeling van die problematiek in het onderwijs waarin chronische decompensatio cordis centraal staat.

Van het beschreven predoctorale kernonderwijs is verder vastgesteld of het zich richt op het verwerven van kennis, vaardigheden en/of attitudes. Onder 'kennis' wordt daarbij zowel feitenkennis verstaan als cognitieve vaardigheden zoals klinisch redeneren. Met 'vaardigheden' wordt gedoeld op handvaardigheden en sociale en communicatieve vaardigheden. Onderwijs rond attitudes is breed opgevat als onderwijs dat betrekking heeft op de houding van de student ten opzichte van anderen (patiënt, familie, collega's, et cetera), waarbij omgang met gevoelens, normen en waarden een rol speelt.

Bij het ziekteoverstijgende onderwijs is ook naar de inrichting van het onderwijs gekeken: wordt het in de vorm van een blok of cursus aangeboden, of verspreid door het curriculum.

Bij de co-assistentschappen is alleen gekeken naar de disciplines waarbij studenten stages lopen. Co-assistentschappen verpleeghuisgeneeskunde, revalidatie en geriatrie zijn beschouwd als stages waarin met name behandeling en begeleiding van chronisch zieken aan de orde is.

Bij het keuzeonderwijs is alleen gekeken naar ziekteoverstijgend onderwijs rond chronisch zieken.

De gemaakte overzichten zijn voorgelegd aan de directeuren van de onderwijsinstituten met het verzoek deze te controleren en zo nodig aan te vullen en/of te corrigeren. Hun is ook gevraagd of er een onderwijslijn chronisch(e) ziek(t)en bestaat en, zo ja, of deze lijn bewaakt wordt en door wie.

Om een beeld te krijgen van de onderwerpen die in het ziekteoverstijgend onderwijs voorafgaand aan de co-assistentschappen aan de orde worden gesteld, zijn de resultaten van de inventarisatie verder geanalyseerd. Een van de auteurs heeft aan alle genoemde onderwerpen een inhoudelijk label toegekend. Met de ontstane set labels heeft de tweede auteur het materiaal opnieuw gecodeerd. Waar bij vergelijking van de labeling discrepanties bestonden, is in gezamenlijk overleg een definitief label gekozen.

\section{Resultaten}

Zeven van de acht faculteiten hebben de gemaakt overzichten gecontroleerd en de open vragen beantwoord. Met hun reacties zijn de overzichten gecompleteerd.

\section{Predoctoraal kernonderwijs}

Bij de ordening van het predoctorale onderwijs rond chronisch zieken zijn negentien verschillende onderwerpen gevonden, die in drie overkoepelende thema's kunnen worden ondergebracht: psychosociale en maatschappelijke aspecten van chronische ziekte, de beroeps uitoefening door de arts en de organisatie van de gezondheidszorg (tabel 1). Van de negentien gevonden onderwerpen worden er per faculteit één tot negen behandeld. Geen enkel onderwerp komt aan alle faculteiten aan bod.

Aan alle faculteiten wordt kennis over chronisch zieken verworven, maar het aantal onderwerpen dat aan bod komt varieert van één tot negen. Aandacht voor attitudes is er bij drie faculteiten en daarbij komen één tot zeven onderwerpen aan bod. Nergens wordt melding gemaakt van het systematisch trainen van vaardigheden. Wel laten vier van de acht faculteiten hun studenten een interview afnemen bij een chronisch zieke. 
Tabel 1. Resultaten van de inventarisatie van ziekteoverstijgend onderwijs rond chronisch zieken in de curricula van de Nederlandse faculteiten geneeskunde geordend naar onderwerp. Uit de kolom waarin een + staat, is af te lezen aan welke faculteit(en) onderwijs in het betreffende onderwerp gegeven wordt en of dit gericht is op kennis, vaardigheden en/of attitude.

\begin{tabular}{|c|c|c|c|c|c|c|c|c|c|c|c|c|c|c|c|c|c|c|c|}
\hline \multirow[b]{2}{*}{ Onderwerpen } & \multicolumn{8}{|c|}{$\begin{array}{l}\text { Kennis } \\
\text { Faculteit } 1 \mathrm{t} / \mathrm{m} 8\end{array}$} & \multicolumn{5}{|c|}{$\begin{array}{l}\text { Vaardigheden } \\
\text { Faculteit } 1 \mathrm{t} / \mathrm{m} 8\end{array}$} & \multicolumn{6}{|c|}{$\begin{array}{l}\text { Attitude } \\
\text { Faculteit } 1 \mathrm{t} / \mathrm{m} 8\end{array}$} \\
\hline & 1 & 2 & 3 & 4 & 5 & 6 & 7 & 8 & 1 & 2 & 34 & 56 & 78 & 1 & 23 & 34 & 56 & 67 & 8 \\
\hline \multicolumn{20}{|c|}{ Psychosociale en maatschappelijke aspecten } \\
\hline $\begin{array}{l}\text { - psychosociale aspecten van } \\
\text { chronische ziekte }\end{array}$ & & + & + & + & & & + & + & & & & & & & & & & & \\
\hline - ziektebeleving/ziektegedrag & & + & & & + & & + & & & & & & & & & + & + & & \\
\hline - afhankelijkheid van de patiënt & & + & & & + & & & & & & & & & & & & + & & \\
\hline - seksualiteit en ziekte & & + & + & & & & & + & & & & & & & & & & & \\
\hline - kwaliteit van leven & & & & & + & & + & & & & & & & & & & + & & \\
\hline - relaties (gezin, familie, etc.) & & + & & & + & & & & & & & & & & + & & + & & \\
\hline - chronisch zieken en arbeid & & & & & + & & & & & & & & & & & & + & & \\
\hline \multicolumn{20}{|l|}{ Beroepsuitoefening van de arts } \\
\hline - 'zorg op maat' & + & & & & & & & & & & & & & & & & & & \\
\hline - samenwerken & + & & & + & & & & & & & & & & & & & & & \\
\hline - palliatieve zorg & + & & & & & & & & & & & & & & & & & & \\
\hline - stervensbegeleiding & & & & & & & + & & & & & & & & & & & & \\
\hline - medisch-ethische aspecten & & & & & + & & + & & & & & & & & & & + & & \\
\hline - relatie hulpverlener-patiënt & & + & & & + & & & & & & & & & & & + & + & & \\
\hline - begeleiding & & + & & & & & & & & & & & & & & & & & \\
\hline - zorgcoördinatie & + & & & & & & & & & & & & & & & & & & \\
\hline \multicolumn{20}{|l|}{ Gezondheidszorg } \\
\hline $\begin{array}{l}\text { - organisatie van de zorgverle- } \\
\text { ning }\end{array}$ & + & + & + & & + & + & & + & & & & & & & & & & & \\
\hline $\begin{array}{l}\text { - niet professionele zorgverle- } \\
\text { ning (mantelzorg) }\end{array}$ & + & & & & & & + & & & & & & & & & & & & \\
\hline - professionele zorgverleners & & + & & & & & + & & & & & & & & & & & & \\
\hline $\begin{array}{l}\text { - ongezonde levensverwachting/ } \\
\text { ontwikkelingen in de zorg }\end{array}$ & & & + & & & & & & & & & & & & & & & & \\
\hline
\end{tabular}


Tabel 2 laat zien welke onderwerpen er aan de orde worden gesteld in het kader van het onderwijs rond specifieke aandoeningen (COPD, reumatoïde artritis, et cetera).

Drie van de acht faculteiten bieden ziekteoverstijgende onderwerpen aan in de vorm van een blok of cursus met een omvang van respectievelijk 160, 120 en 80 uur (tabel 3). Deze drie faculteiten besteden in dit onderwijs vooral aandacht aan niet-biomedische aspecten: aan de ene kant ziektebeleving en ziektegedrag en aan de andere kant de organisatie van de zorg. De werkvormen die gebruikt worden zijn colleges, zelfstudieopdrachten waarbij een werkstuk vervaardigd wordt, en het interview met een patiënt.

\section{Overig onderwijs}

Aan twee faculteiten worden co-assistentschappen gerealiseerd waarin de zorg voor chronisch zieken centraal staat. Aan de ene faculteit is dat een co-assistentschap ver- pleeghuisgeneeskunde en aan de andere een co-assistentschap revalidatie. Drie van de acht faculteiten bieden specifiek keuzeonderwijs rond chronisch zieken.

\section{Onderwijslijn chronisch zieken}

Aan geen van de faculteiten bestaat een onderwijslijn over chronisch zieken. Bij de Katholieke Universiteit van Nijmegen is het blok 'chronisch ziek-zijn' onderdeel van de lijn 'grondslagen en methoden'. Deze lijn bevat de meer reflectieve aspecten rondom ziekte en gezondheid, geneeskunde en medische wetenschap en wordt bewaakt door een lijncommissie.

\section{Discussie}

Ons onderzoek laat zien dat er aan alle Nederlandse faculteiten aandacht wordt besteed aan chronische ziekte. De aandacht per faculteit varieert echter sterk en van alle gevonden onderwerpen komt nooit meer dan de helft aan bod.

Tabel 2. Resultaten van de inventarisatie van ziektegebonden onderwijs rond chronisch zieken in de curricula van de Nederlandse faculteiten geneeskunde geordend naar onderwerp. Uit de kolom waarin een + staat, is af te lezen aan welke faculteit(en) onderwijs in het betreffende onderwerp gegeven wordt en of dit gericht is op kennis, vaardigheden en/of attitude.

\begin{tabular}{|c|c|c|c|c|c|c|c|}
\hline \multirow[b]{2}{*}{ Onderwerpen } & \multicolumn{7}{|c|}{$\begin{array}{l}\text { Kennis } \\
\text { Faculteit } 1 \mathrm{t} / \mathrm{m} 8\end{array}$} \\
\hline & 1 & 2 & 34 & 5 & 6 & 7 & 8 \\
\hline \multicolumn{8}{|c|}{ Psychosociale en maatschappelijke aspecten } \\
\hline $\begin{array}{l}\text { - psychosociale aspecten van } \\
\text { chronische ziekte }\end{array}$ & & + & + & + & & & \\
\hline \multicolumn{8}{|l|}{ Beroepsuitoefening van de arts } \\
\hline $\begin{array}{l}\text { - stoornissen, beperkingen, han- } \\
\text { dicaps }\end{array}$ & + & & & & & & \\
\hline - samenwerken & & & & & + & & \\
\hline - palliatieve zorg & & & & + & & & \\
\hline - stervensbegeleiding & & & & & & & \\
\hline - medisch-ethische aspecten & + & & & & + & & \\
\hline
\end{tabular}
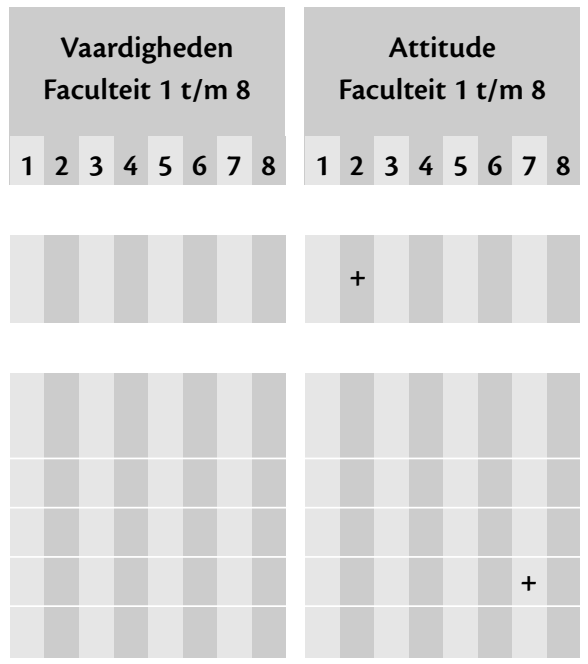
Tabel 3. Ziekteoverstijgend onderwijs als blok of cursus aan de acht Nederlandse faculteiten geneeskunde.

\begin{tabular}{|c|c|c|c|c|c|c|}
\hline faculteit & onderwerpen & jaar & onderwijsvorm & (uren) & & $\begin{array}{l}\text { ivar } \\
\text { V }\end{array}$ \\
\hline 1 & $\begin{array}{l}\text { oorzaken en gevolgen van } \\
\text { chronisch ziek-zijn; } \\
\text { organisatie van de zorg; } \\
\text { planmatige zorg; palliatieve zorg }\end{array}$ & 4 & $\begin{array}{l}\text { hoorcolleges, } \\
\text { werkgroepen, practica, } \\
\text { werkstuk of case-study }\end{array}$ & 160 & K & \\
\hline 2 & $\begin{array}{l}\text { de chronische patiënt/ } \\
\text { chronisch ziek-zijn }\end{array}$ & 1 & $\begin{array}{l}\text { zelfstudieopdrachten, } \\
\text { interview patiënt met } \\
\text { voor- en nabespreking }\end{array}$ & 80 & & V \\
\hline 5 & $\begin{array}{l}\text { hoe chronisch zieken en hun } \\
\text { directe omgeving met de ziekte } \\
\text { omgaan; } \\
\text { verwachtingen t.a.v. hulpverlening; } \\
\text { organisatie van de zorg }\end{array}$ & 3 & $\begin{array}{l}\text { werkstuk, gastcollege } \\
\text { (patiënt en hulpverleners); } \\
\text { discussie; interview } \\
\text { patiënt en hulpverlener }\end{array}$ & 120 & K & V \\
\hline
\end{tabular}

$\mathrm{K}=$ Kennis $\mathrm{V}=$ Vaardigheden; $\mathrm{A}=$ Attitude.

De gebruikte inventarisatie via studiegidsen levert natuurlijk een grof beeld op van het onderwijs en er kunnen discrepanties bestaan tussen wat er in een studiegids staat en wat er in de praktijk gebeurt. Omdat de bevindingen gecontroleerd en aangevuld zijn door de faculteiten is binnen deze beperkingen toch sprake van een betrouwbaar beeld van het onderwijsaanbod.

Cohen geeft een overzicht van de competenties waarover een arts moet beschikken om adequaat om te kunnen gaan met chronisch zieken. ${ }^{12}$ Hij beredeneert dat de basis op al deze gebieden tijdens de studie geneeskunde gelegd moet worden en dat verdere uitbouw tijdens de vervolgopleidingen plaats moet vinden. Met onderwijs rond de competenties die in het artikel genoemd worden, verwerven studenten inzicht in de gevolgen van een chronische aandoening voor de patiënt en diens omgeving, de complexiteit en samenhang van professionele en mantelzorg, en de rol van de arts daarin. Alle onderwerpen die wij in de Nederlandse studiegidsen gevonden hebben, zijn volgens het overzicht van Cohen relevant voor elke arts (alleen 'zorg op maat' is er niet in onder te brengen). Gezien onze bevindingen is op dit moment de dekking van onderwerpen rond chronisch zieken aan geen enkele faculteit compleet.

Wat verder opvalt, is de nadruk die in de studiegidsen wordt gelegd op het verwerven van kennis en het trainen van klinisch redeneren. Deze twee elementen vormen een belangrijke basis voor het medisch handelen, maar in het contact met patiënten, hun naasten en met andere hulpverleners is meer dan dat vereist. Bijvoorbeeld een goede toepassing van communicatieve vaardigheden en een adequate omgang met attitudes. Zoals ook Cohen in zijn artikel stelt, moet juist daaraan in het onderwijs voor studenten geneeskunde uit- 
gebreid aandacht worden besteed. ${ }^{12}$ Op dit moment is dat in Nederland niet het geval. Vier van de acht faculteiten laten studenten eenmalig een chronisch zieke interviewen, maar van herhaling daarvan of van specifieke trainingen in het vaardigheidsonderwijs (zoals het trainen van vervolgconsulten) wordt geen melding gemaakt.

Samenvattend ontbreekt het bij de Nederlandse faculteiten geneeskunde aan systematische aandacht voor de gevolgen van chronische aandoeningen op psychosociaal en maatschappelijk terrein en de rol van de arts op die gebieden. De aandacht die er is, gaat onevenredig sterk naar kennisverwerving, en er bestaan grote lacunes op het gebied van vaardigheden en attitudebewustwording. Gezien deze bevindingen willen we ons graag aansluiten bij de adviezen die we in de inleiding aanhaalden. Dat doen we met enige schroom, want tot op heden lijken die adviezen niet tot veel veranderingen geleid te hebben. Ons artikel staat voorlopig aan het eind van een reeks die al ruim drie decennia duurt en waarvan de teneur niet verandert: steeds wordt geconstateerd dat artsen niet adequaat worden voorbereid op hun contacten met chronisch zieken. Dit moet natuurlijk niemand ervan weerhouden om de lacunes in de eigen curricula op te sporen en aan te vullen, maar het roept wel vragen op naar de redenen waarom er zo weinig veranderd lijkt te zijn.

Het project 'Onderwijs rond chronisch zieken in C2000' is mede mogelijk gemaakt door een subsidie van ZorgOnderzoek Nederland (projectnummer 9807021). Nadere informatie over het project en de resultaten ervan zijn te vinden op de website http://coo.med.rug.nl/fmw/pcz.htm.

\section{Literatuur}

1. Ruwaard D, Kramers PGN, redactie. Volksgezondheid Toekomst Verkenning 1997. De som der delen. Maarssen: Elsevier/De Tijdstroom; 1997.

2. Directie Voorlichting en Communicatie. Factsheet chronisch ziekenbeleid (FS 06-N-1997). Rijswijk: Ministerie van Volksgezondheid, Welzijn en Sport; 1997.

3. Chronisch Zieken aan zet; tussenbalans chronisch ziekenbeleid 1991-1994. Zoetermeer: Nationale Commissie Chronisch Zieken; 1994.

4. Chronisch zieken, uw zorg? Onderwijsarrangement over de begeleiding door de huisarts van mensen met een chronische ziekte. NHG/LHVDeskundigheidsbevorderingspakket 53. Utrecht: Nederlands Huisartsen Genootschap; 1997.

5. Rapaport HG. Chronic illness. Ann Allergy 1968;26(5):230-2.

6. Charlton R. The philosophy of palliative medicine: a challenge for medical education. Med Educ 1992;26(6):473-7.

7. Kutner NG. Medical students' orientation toward the chronically ill. J Med Educ 1978;53(2):111-8.

8. Lehmann JF. Patient care needs as a basis for development of objectives of physical medicine and rehabilitation teaching in undergraduate medical schools. J Chronic Dis 1968;21(1):3-12.

9. Greenberg LW. Pediatric patient education: the unanswered challenge to medical education. Patient Educ Couns 1991;17(1):3-7.

10. Pawlson LG. Clinical medical education in the nursing home: opportunities and limits. J Med Educ 1982;57(10 Pt 1):787-91.

11. Verbeek AMM, Metz JCM, Fiolet JFBM. Project landelijke coördinatie geriatrie onderwijs (LCGO). In: Spaai GWG, Verweij AMJJ, Remmen R, Dolmans DHJM, Denekens JPM, Smal JA, et al., redactie. Gezond Onderwijs 8. Houten/ Diegem: Bohn Stafleu Van Loghum 1999; p. 310-3.

12. Cohen AJ. Caring for the chronically ill: a vital subject for medical education. Acad Med 1998;73(12):1261-6.

13. Pols J, Rijswijk MH van, Zwierstra RP, Meininger AK, Aukes LC, Albada BL van, et al. Project 'onderwijs rond chronisch zieken in C2000'. In: Spaai GWG, Verweij AMJJ, Remmen R, Dolmans DHJM, Denekens JPM, Smal JA, et al., redactie. Gezond Onderwijs 8. Houten/Diegem: Bohn Stafleu Van Loghum 1999; p. 240-3. 
De auteurs:

J. Pols, arts-onderwijskundige, is als arts werkzaam bij de Afdeling Onderwijsontwikkeling en Kwaliteitszorg van het Onderwijsinstituut van de Faculteit der Medische Wetenschappen van de Rijksuniversiteit Groningen en bij de stafgroep Organisatie en Ontwikkeling van het Academisch Ziekenhuis Groningen. Hij is projectleider van het project 'Onderwijs rond chronisch zieken in C2000'.

J. van der Griend, bedrijfsarts, ARBO Unie Heerenveen, was ten tijde van het onderzoek werkzaam bij de
Faculteit der Medische Wetenschappen van de Rijksuniversiteit Groningen als projectmedewerker bij het project 'Onderwijs rond chronisch zieken in C2000'.

Correspondentieadres:

J. Pols, Faculteit der Medische Wetenschappen, Afdeling Onderwijsontwikkeling en Kwaliteitszorg, A. Deusinglaan 1, geb 3216, kamer 113, 9713 AV Groningen, tel.: 050363 76 29, fax: 05036338 65, e-mail: j.pols@med.rug.nl.

\section{Summary}

Introduction: A doctor's performance should not only be adequate in medical biological terms but also regarding the psychological and social consequences of illness. Patients think that the attention they receive from doctors is less than satisfactory regarding the latter two aspects. The lack of adequate preparation of doctors in this respect has been emphasised in numerous articles since 1966.

Purpose: We wanted to obtain an overall picture of the attention given to chronic illness in the curricula of the Dutch medical faculties. In particular we were interested in the psychological and social aspects, and the doctor's role in this as well as in the distribution of educational efforts over knowledge, skills and attitudes.

Method: We collected information from the study guides and had this checked by the heads of the Departments of Education of the Faculties of Medicine. A distinction was made between generic and disease related educational activities. Of the courses in the preclinical phase it was determined whether the focus of the course was knowledge, skills or attitudes. The courses were categorised by subject.

Results: The attention paid to chronic illness proved to be mainly focused on biomedical subjects and theoretical knowledge. Psychological and social aspects receive limited attention and are absent from skills courses and clerkships.

Conclusion: Dutch medical schools should seriously address the gaps in undergraduate medical training with respect to the psychological and social consequences of chronic illness. At this point Dutch curricula have failed to adapt to changes in the Dutch health care system. (Pols J, Griend J van der. The teaching of subjects related to chronic illness in the Dutch undergraduate medical curricula. Dutch Journal of Medical Education 2001;20(2):46-53.) 